\title{
Characterizing Barley Seed Macro- and Micro-nutrients under Multiple Environmental Conditions
}

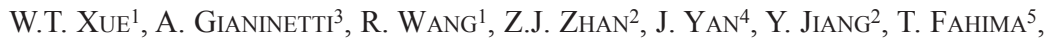 \\ G. ZHAO ${ }^{4 *}$ and J.P. CHENG ${ }^{2 *}$ \\ ${ }^{1}$ College of Life Sciences, Guizhou University, Guiyang, Guizhou 550025, China \\ ${ }^{2}$ College of Agriculture, Guizhou University, Guiyang, Guizhou 550025, China \\ ${ }^{3}$ Consiglio per la ricerca in agricoltura e l'analisi dell'economia agraria, Genomics Research Centre, \\ Fiorenzuola d'Arda, PC 29017, Italy \\ ${ }^{4}$ School of pharmacy and bioengineering, Chengdu University, Chengdu, Sichuan 610106, China \\ ${ }^{5}$ Institute of Evolution, Faculty of Natural Sciences, University of Haifa, Haifa 31905, Israel
}

(Received 3 February 2016; Accepted 27 April 2016;

Communicated by M. Molnár-Láng)

\begin{abstract}
Crop seeds are the main staples in human diet, especially in undeveloped countries. In any case, the diet needs to be rich not only in macro-nutrients like carbohydrates and protein, but also in micro-nutrients. Nevertheless, both the macro- and micro-nutrients presented in seeds largely vary in consequence of field and environment conditions. In this research, 60 lines of a barley RILs population segregating for the SSR marker Hvm74, which is genetically linked to the GPC (grain protein content) locus (HvNAM-1), were studied in 4 environments (two growing years and two field managements) by carrying out a comprehensive profile of seed macro- (starch, total nitrogen and total soluble protein) and micro-nutrients (phytate, phenolics, flavonoids, $\mathrm{P}_{\mathrm{i}}, \mathrm{Zn}$ and $\mathrm{Fe}$ ). Under field conditions, all the components were largely affected by the environment, but TN (total nitrogen) exhibited high genotype contribution, while micro-nutrients displayed higher genotype $\times$ environments interactions (GEI) than macro-nutrients. In order to approach the effects of carbon-nitrogen $(\mathrm{C}-\mathrm{N})$ balance on other seed components, two $\mathrm{C} / \mathrm{N}$ ratios were calculated: $\mathrm{C} / \mathrm{TN}$ (CNR1) and C/TSP (CNR2). CNR2 exhibited stronger negative correlations with all micro-nutrients. Hence, the significant GEI and its negative relationships with CNR2 highlighted the different characters of micro-nutrients in barley seeds.
\end{abstract}

Keywords: seed component, macro-nutrient, micro-nutrient, genotype $\times$ environments interactions, carbon/nitrogen ratio, $\mathrm{Hvm} 74$

\section{Introduction}

Carbon (C) and nitrogen (N) are the major elements stored in crop seeds which highly related to the final crop yield (Triboi and Triboi-Blondel 2002). Robust evidences from field trials suggested remarkable negative correlations between GPC and total yield (Blanco et al. 2012). Genetically, GPC locus (HvNAM-1), a homologous gene of GPC-

*Corresponding authors; E-mails: zhaogang@cdu.edu.cn; chengjianping63@qq.com; Phone: +86-2884616628; +86 13765006312; Fax: +868513855894 
B1(TtNAM-B1) from wild emmer wheat (Triticum dicoccoides) (Uauy et al. 2006), was detected in barley that controls leaf senescence and resulted in $\mathrm{N}$ remobilization (Distelfeld et al. 2008), thereby also enhanced barley GPC (Parrott et al. 2011). However, the direct relationship between $\mathrm{C}$ compositions and GPC locus has not yet been reported in barley, even though $\mathrm{C}$ compounds are the major components in barley seeds.

There are plenty of seeds components with levels lower than $1 \%$ of total grain, which are regarded as 'micro-nutrients', but played crucial roles for human health. In spite of the high heritability obtained in greenhouse conditions (Mamo et al. 2014), this group of traits exhibited low heritability (Joshi et al. 2010) in fields since the prevailing effects of environments (Marwede et al. 2004). The genotype $\times$ environment interactions (GEI) are the major sources for phenotypic variation in micro-nutrients and have been investigated in wheat (Ficco et al. 2009). Few studies were devoted to the relationships between macro- and micro-nutrients (Gomez-Becerra et al. 2010). Specifically, the general relationships between micro-nutrients and $\mathrm{C}-\mathrm{N}$ balance are still poorly understood in seeds. Phosphorus (P) does not belong to micro-elements in plants because of its large percentage in dry matter. However, the total $\mathrm{P}$ in dry seeds is lower than $1 \%$ of total grain and could therefore be classified as micro-nutrient in seed researches. In addition to its functions for human diet, seed $\mathrm{P}$ is considered to be of benefit for seedling establishment and finally crop yields (White and Veneklaas 2012).

Considering the plenty of environmental experiments on seed components, large cultivar collections are commonly taken as materials to observe the complicate GEI by several mathematic models (Joshi et al. 2010), but the diverse genetic background might enlarge their GEI. Moreover, these studies are often lacking of a comprehensive profiling for seed components (Hristov et al. 2010). In barley seeds, the GEI of seed components are frequently combined with studies of malting quality for further investigation (Holopainen et al. 2015). Notwithstanding it is a C-accumulating seed crop, in barley the $\mathrm{C}-\mathrm{N}$ balance is also rarely observed under multiple environments. Therefore, in our study, 60 lines of bi-parental RILs population with simple genetic background were investigated for GEI on both macro- and micro-nutrients with comprehensive profiling of seed components among 4 different environments, the further effects of $\mathrm{C}-\mathrm{N}$ balance on micro-nutrients were also characterized in this study.

\section{Materials and Methods}

\section{RILs and field experiments}

Sixty lines of 146 barley RILs population were chosen as material basing on its segregation on SSR marker Hvm 74 on chromosome $6 \mathrm{H}$ which was demonstrated to be tightly linked to the GPC locus (Distelfeld et al. 2008). The RILs population was obtained by crossing cultivar "Karl"(6-row) and "Lewis"(2-row) which also proved to be diverse at GPC trait (Parrott et al. 2011). All the 60 barley lines belong to six-row type. Field experiments carried out at two Yunnan-Guizhou plateau sites including Guiyang (Site 1, $26^{\circ} 34^{\prime} \mathrm{N}, 106^{\circ} 27^{\prime} \mathrm{E}, 1100 \mathrm{~m}$ a.s.1) and Anshun (Site 2, 26 $6^{\circ} 5^{\prime} \mathrm{N}, 105^{\circ} 55^{\prime} \mathrm{E}, 1395 \mathrm{~m}$ a.s.l), 
Guizhou province of P. R. China. Two types of environment were applied to profile the seed components including different growing years and field managements. Two growing years were completed at Site 1 during years of 2010-2011 (Y2011) and 2011-2012 (Y2012) without fertilization. Whereas, two field managements were conducted at Site 2 during years of 2012-2013 but distinct by two fertilizer conditions, one set was fertilized by $30 \mathrm{~kg} / \mathrm{ha} \mathrm{N}: \mathrm{P}: \mathrm{K}$ 15:15:15 (Y2013F), comparing to the other condition without any fertilizations (Y2013NF). All barley seeds were sowed in furrows (headrows) over all field conditions with $1.5 \mathrm{~m}$ width and $50 \mathrm{~cm}$ intervals. The fertilizations were applied into furrows directly during seed sowing. Three replicates were made by randomized block design in each field, respectively. The soil samples of all field sites were collected at the depth of 0-30 cm and analyzed with parameters of $\mathrm{pH}$, organic matter content and element concentrations. Seeds sample were cleaned and grinded into wholemeal flour by FastPrep-24 Automated System (MP Biomedicals, USA), then filtered by $0.45 \mathrm{~mm}$ sieve and dried in oven at $40{ }^{\circ} \mathrm{C}$ for a week before the analysis.

\section{Analysis of seed components}

Starch (Sta) was conducted by Megazyme Kit (K-TSTA 07/11) and the procedures were modified from the AACC76.13/AOAC996.11. TN was determined by Kjeldahl method using Tecator Kjeltec 8400 (FOSS, Sweden). The parameter of GPC was multiplied by coefficient of 5.68. Total soluble protein (TSP) was analyzed by UV-Spectrophotometer (Beckman, USA) based on the BCA protocol.

Total flavonoid (Fla), phenolics (Phe), phytate (Phy) and inorganic phosphorus $\left(\mathrm{P}_{\mathrm{i}}\right)$ content were determined by stepwise extractions on one sample. Samples were extracted by $50 \%$ methanol following $1 \mathrm{~h}$ ultrasonic treatment, $30 \mathrm{~min}$ water bath at $65{ }^{\circ} \mathrm{C}$ and 30 min shaking at room temperature by PCMT Thermo-Shaker (Grant-bio, UK). After 10 min centrifuge, samples were placed at $4{ }^{\circ} \mathrm{C}$ with minimum $48 \mathrm{~h}$ for sugar sedimentation. The supernatants were measured for Fla and Phe content, respectively. The residues were vacuum-dried by Concentrator Plus (Eppendorf, Germany) for $8 \mathrm{~h}, 0.5 \mathrm{M} \mathrm{HCl}$ was added to extract residues and the supernatants were measured for Phy and $\mathrm{P}_{\mathrm{i}}$ content independently. Fla content was determined by the method of Jia et al. (1999). The Folinphenol method (Ainsworth and Gillespie 2007) was applied to determine the Phe content. The supernatants after second extraction were analyzed for Phy based on Wade reagent (Latta and Eskin 1980). The Pi content was measured by the methods of Ficco et al. (2009).

For the mineral determination of $\mathrm{Zn}$ and $\mathrm{Fe}$, samples were digested with $\mathrm{HNO}_{3}(65 \%)$ by MARS5 microwave digestion system (CEM Analytical, USA). The diluted solutions after digestion were analyzed for $\mathrm{Zn}$ and Fe concentrations by atomic absorption spectrometry (AA6000, Techcomp, China). Single kernel weight (SKW) and hundreds kernel weight $(\mathrm{HKW})$ were measured independently considering the seeds variation in the sixrow type of barley, repeating 10 and 4 times, respectively. 


\section{Statistical analysis}

Two-way ANOVA was carried out by STATISTICA7 (StatSoft, USA) considering genotypes $(\mathrm{G})$ as a fixed factor and environment (E) as a random factor, wherein the data were transformed by $\log _{10}$. Nested ANOVA was conducted with genotypes nested in haplotype (Hvm 74). Tukey HSD was applied by JMP 6.0. Principal component analysis (PCA) were conducted by software PAST and the graphs were drew by Sigmaplot 12.0 with data normalization of dividing average values. Pearson correlation matrix was calculated by $\mathrm{R}$ 2.1.1 with same data normalization as PCA, then were visualized into networks using the open source bioinformatics software platform Cytoscape 2.8.1.

\section{Results}

\section{Profiling of barley seed components from multiple environments}

The brief soil conditions and average temperature information from three filed sites have been described in Table $\mathrm{S}^{*}$, which were highlighted by variations of $\mathrm{T}_{\text {april }}$, soil $\mathrm{pH}, \mathrm{Mg}$ and Mn. In PCA of all seed traits (Fig. 1), 4 environments are significantly separated by first two components which explain $60.1 \%$ of total variation. Seed components in Y2013F

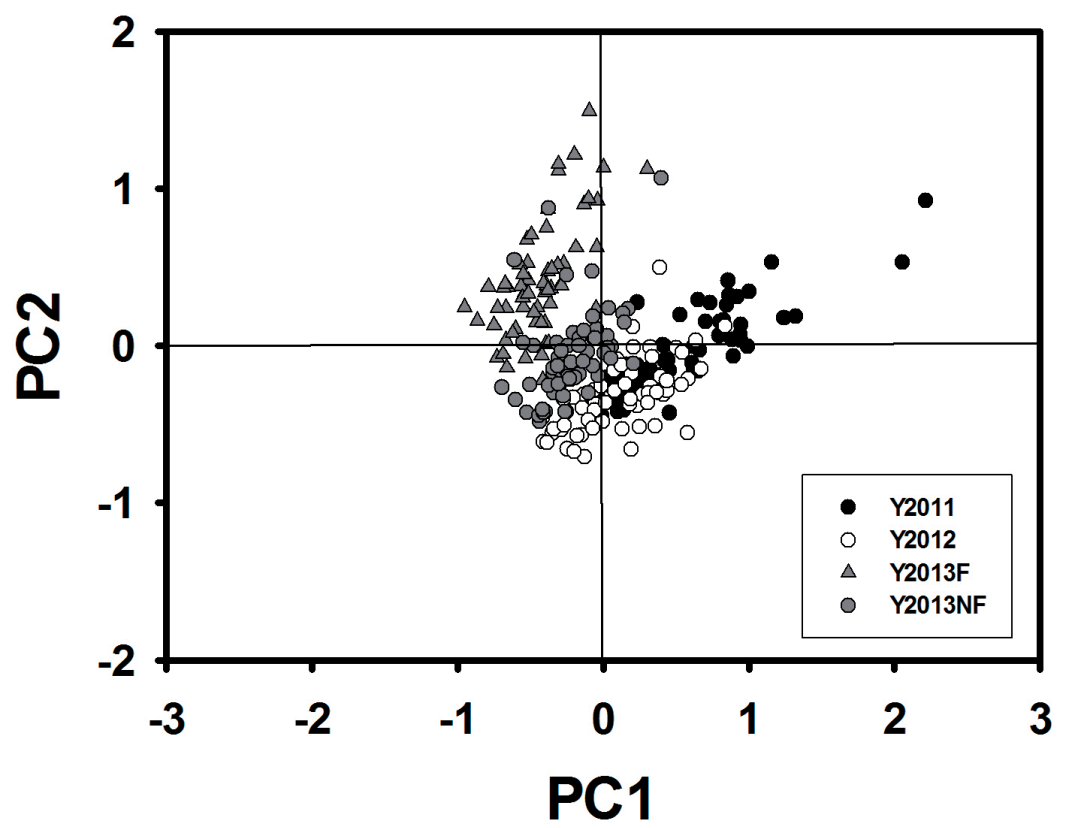

Figure 1. Principal component analysis of barley seed components, HKW and SKW in 4 environments. The first two components explain $36.1 \%$ and $24.0 \%$ of variations, respectively

*Further details about the Electronic Supplementary Material (ESM) can be found at the end of the article. 
are clearly shifted from other environments suggesting the strong influences from the field managements. Meanwhile, the large variations between Y2011 and Y2012 also proved the significant effects from different growing years which varied in both soil and weather conditions (Table S1), wherein the unfavorable temperature during seed developments and its relatively lower micro-nutrients in soil condition were found Y2011. Nine seed components of 60 RILs and 2 parents from 4 environments are exhibited in Fig. S1, as well as HKW and SKW. Briefly, Sta and TN were accumulated among 4 environments in a contrary way; whereas this pattern was not clearly followed by the micro-nutrients.

\section{Effects $C-N$ balance on barley seed components and correlations between macro/ micro-nutrients}

Two $\mathrm{C} / \mathrm{N}$ ratios were calculated in Fig. $\mathrm{S} 1$ using Sta as $\mathrm{C}, \mathrm{GPC}(\mathrm{C} / \mathrm{N}$ ratio $1, \mathrm{CNR} 1)$ or TSP (C/N ratio 2, CNR2) as N, concomitant with average ratio of $6: 1$. There are significances in CNR1 among all environments but no significant difference between Y2013F and Y2013NF in CNR2. This result proved that field managements could alter CNR1 but not CNR2, and indicated TSP is more stable in barley grain than TN. Correlation-based networks were applied on all environments dataset and the interactions between groups of macro- and micro-nutrients were illustrated in Fig. 2A. Strong correlations from Phy and Phe to TSP were positively linked with the reversed patterns to Sta. The core networks of CNR were highlighted in Fig. 2B with uncorrelated traits of SKW and HKW. Interestingly, CNR2 was negatively correlated with all micro-nutrients but CNR1 only showed two links with $\mathrm{P}_{\mathrm{i}}$ and Fe. The CNR2 improved the correlations with micronutrients comparing to the individual $\mathrm{C}$ and $\mathrm{N}$ in Fig. $2 \mathrm{~A}$.

\section{ANOVA for GEI and haplotype Hvm74}

Environments had significant effects $(p<0.001)$ on all traits and specifically large contributions to Sta, TN and Zn, but these effects were minor to Phy and $\mathrm{P}_{\mathrm{i}}$, as well as HKW and SKW (Table S2). In antioxidants, Phe is less affected than Fla by multiple environments. Also, TSP is less influenced by environments than TN. However, genotypes contributed different significances to seed components. There are no significances observed between genotypes in traits of Sta, TSP, phytate, Phe and $\mathrm{P}_{\mathrm{i}}$, but significances with $p<0.001$ in traits of TN, Fe, HWK and SKW, and significances with $p<0.05$ in traits of Fla and Zn. These results suggested that macro-nutrients of $\mathrm{C}$ (starch), soluble $\mathrm{N}$ (total soluble protein), and $\mathrm{P}$ (phytate and $\mathrm{P}_{\mathrm{i}}$ ) of barley grains were not inherited in this RILs population, whereas, micro-nutrients of Fla, $\mathrm{Zn}$ and Fe exhibited high hereditary under multiple environments. GEI showed no significances in Sta and TSP, these results were same as genotype contributions. High levels of GEI were observed in all micro-nutrients except $\mathrm{Zn}$ and Fe. Two types of $\mathrm{C} / \mathrm{N}$ ratios displayed similar results as TN and TSP, respectively.

The segregation of Hvm 74 divided 60 lines into 34 and 26 lines with "Lewis" and "Karl" alleles, respectively. In the nested ANOVA (Table S3), genotype was nested in the 


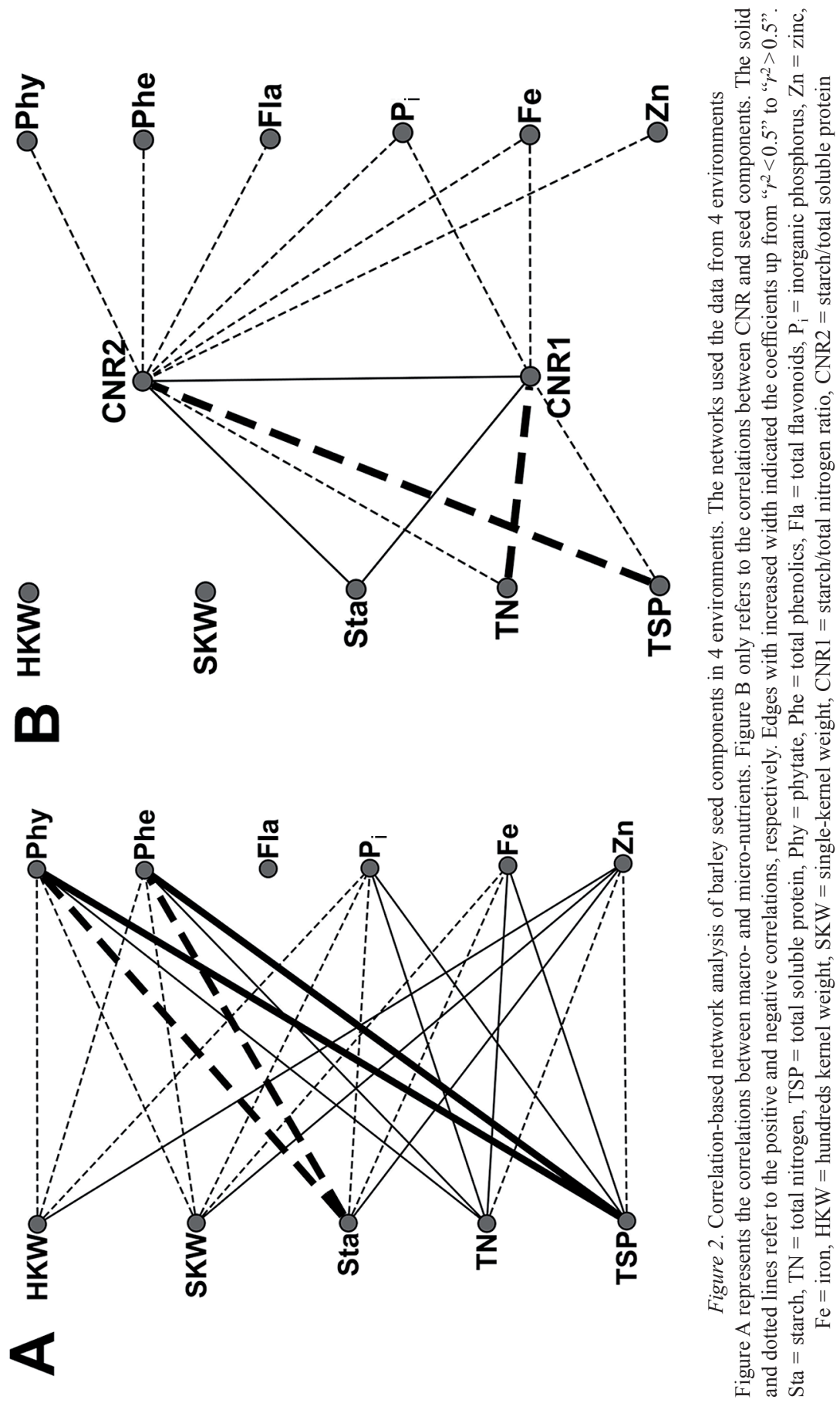

Cereal Research Communications 44, 2016 
haplotype Hvm 74. The traits of Sta, TN, Fe and CNR1 displayed significances in haplotype contributions with $p<0.001$. However, genotype-nested-Hvm74 exhibited significant contributions to TN, Fe and CNR1 but not to Sta. Moreover, the contributions of genotype-nested-Hvm 74 in these three traits are much higher than the contribution from haplotype, which indicated that Hvm 74 is still not the major factor for those traits. In addition, haplotype Hvm 74 also exhibited significances on traits of Phy and Fla but with minor contributions.

\section{Discussion}

\section{Macro- and micro-nutrients of barley seeds give different GEI}

Seed components are classified according to their levels, which are associated with different GEI under multiple environments. The GEI of GPC and Sta under multi-environments trials have been discussed by plenty of studies, with general opinions that both GPC and Sta are genetically controlled (Bao et al. 2004; Souza et al. 2004) but also largely influenced by environmental factors (Zhang et al. 2001). Their GEI could be as large as the contribution of the genotype (Jeuffroy et al. 2014). In our study, Sta not only showed low GEI, but also low genotype contributions, mainly due to the non-significance of the difference in Sta content between bi-parents. In contrast, TN exhibited $21 \%$ variation due to genotype, which is twice higher than the corresponding value of GEI. Thus, the GEI of TN is relatively lower than the percentage of variability explained by environment and genotype, thereby supporting that genetic materials with simpler genetic background might reduce the GEI of corresponding traits. However, TSP did not show the same results as TN for both genotype and GEI contributions. Apparently, TSP is not strictly related to GPC under multiple environments. This suggests that other nitrogen-containing components, like insoluble proteins and inorganic nitrogen, show a large GEI.

In our results, all the micro-nutrients were largely affected by environments, wherein Zn (47\%) exhibited highest environmental contributions in ANOVA results (Table S2) and might be influenced by the varied soil $\mathrm{Zn}$ contents among three field sites. However, different soil Fe contents were also detected but concomitant with relatively lower contributions (27\%) from environments in ANOVA, which might be offset by the positive effects from GPC locus with supports from nested ANOVA (Table S3). Moreover, 4 traits of Phy (51\%), Phe (43\%), Fla (33\%) and $\mathrm{P}_{\mathrm{i}}(43 \%)$ displayed higher GEI than $\mathrm{Zn}$ and Fe, which emphasized the distinguished characters of antioxidants and $\mathrm{P}$ portions from micro-elements. High GEI of antioxidants in other crop seeds has been observed with 35\% of Phe and $\sim 30 \%$ of other antioxidants in durum wheat (Brankovic et al. 2015). Similarly, $34.7 \%$ and $44.3 \%$ GEI have been found for Phy in bread wheat and durum wheat, respectively (Brankovic et al. 2015), but only 7\% in rice seeds (Liu et al. 2005). In Brankovic's study, $\mathrm{P}_{\mathrm{i}}$ showed relatively lower GEI in both bread wheat $(15.5 \%)$ and durum wheat $(27.0 \%)$, which is different from our barley seeds. High GEI of both Phy and $\mathrm{P}_{\mathrm{i}}$ in barley were probably due to the seed hulls, as it was proved that hulled barley is able to maintain more stable P content, especially the Phy (Liu et al. 2007). Large GEI for Zn (51\%) and 
Fe (54\%) were also observed in durum wheat (Ficco et al. 2009), but slightly lower GEI for $\mathrm{Zn}(31 \%)$ had been observed in spelt wheat (Gomez-Becerra et al. 2010). In milled rice grain, $\mathrm{Zn}$ and Fe exhibited 18\% and 46\% GEI, respectively (Pandian et al. 2011). Few studies reported insignificant and small GEI for both $\mathrm{Zn}$ and Fe in seeds (Joshi et al. 2010). The different GEI of antioxidants and $P$ portions from micro-elements might be due to their distinguished transfer mechanism during seed development. Antioxidants are mainly synthesized during seed maturation, which could be largely affected by environmental conditions during seed desiccation (Caldwell et al. 2005). The P content in seeds also depends on the P utilization efficiency (PUE), which is determined by the available $\mathrm{P}$ in soil (Ozturk et al. 2005). Even the soil total $\mathrm{P}$ was not varied from three site, but the different soil $\mathrm{pH}$ also could largely change the soil available $\mathrm{P}$ and might increase the GEI of seed P portions. The GPC locus might bring potential effects on micro-elements in barley, and its positive effect on Fe has been proved in our study by the nest-ANOVA (Table S3). The remobilization of $\mathrm{N}$ compounds might improve translocation of $\mathrm{Zn}$ and Fe into seeds. Therefore, even the soil micro-nutrients were shifted from three sites, the relatively lower GEI was still observed for $\mathrm{Zn}$ and $\mathrm{Fe}$ in our multiple environments study suggesting the strong genetic influences from GPC locus.

\section{$C-N$ balance in barley seeds and its effects on other components}

$\mathrm{C} / \mathrm{N}$ ratios were investigated in our study, and they showed improved correlations with micro-nutrients than the individual $\mathrm{C}$ and $\mathrm{N}$ nutrients; especially CNR2 exhibited negative correlations with all the micro-nutrients (Fig. 2B). In fact, $\mathrm{C} / \mathrm{N}$ ratio has been used as a parameter in other seed research (He et al. 2005). CNR2 derives from the final levels of hydrolysable starch and soluble protein in dry seeds, which could provide part of information for both actual photosynthesis capacities and $\mathrm{N}$ uptake and remobilization levels. Based on the general opinions of $\mathrm{N}$ priority (Triboi and Triboi-Blondel 2002) in C/N ratios, most negative correlations of CNR2 with micro-nutrients might be contributed by TSP. Since antioxidants mainly belong to secondary metabolites and are synthesized at late seed developmental stage (Routaboul et al. 2006), it is also possible that they are highly related to the soluble protein levels due to the main functions of $\mathrm{N}$ compounds in seeds secondary metabolism (Scheible et al. 2004). The positive correlations between GPC and micro-elements ( $\mathrm{Zn}$ and $\mathrm{Fe}$ ) have been documented (Gomez-Becerra et al. 2010). The roles of $\mathrm{Fe}$ and $\mathrm{Zn}$, which frequently are involved in protein synthesis and $\mathrm{N}$ metabolism, are also reported (Takahashi et al. 2009); for example, Zn-finger protein and nitrate fixation by Fe (Hell and Stephan 2003). However, no significantly negative correlations were found between seed P and GPC in rice seeds (Liu et al. 2005), suggesting the negative correlations between CNR2 and $\mathrm{P}$ compounds (Phy and $\mathrm{P}_{\mathrm{i}}$ ) might be caused by $\mathrm{C}$ compounds. The $\mathrm{C} / \mathrm{N}$ ratio also points out the seeds orientation or adaptation of $\mathrm{C} / \mathrm{N}$ metabolisms under their specific environments. Following the concept of sink-source communication during seed development (Triboi and Triboi-Blondel 2002), lower C/N ratios could be raised by the increased seed-sink strength but mainly by the varied $\mathrm{N}$ remobilization induced by environments. 


\section{Effects of haplotype Hvm74 on seed components}

In the aim of understanding the effects of the GPC locus on seed components in barley seeds, haplotype $H v m 74$ was studied and results proved that it not only had effects on Sta and TN, but it also exhibited a strong effect on Fe. The leaf senescence and N remobilization have been clearly demonstrated in GPC domain lines (Parrott et al. 2011). Even the $\mathrm{Zn}$ and $\mathrm{Fe}$ amounts had been reported to be associated with GPC1 gene in wheat (Pearce et al. 2014), but the Fe enhancement by effect of the GPC locus had not been previously reported for barley seeds. The ions transform of $\mathrm{Zn}$ and $\mathrm{Fe}$ in phloem in is still not clearly understood, but the GPC-B1 gene has been assumed to encode transporters or chelators for their mobilizations into seeds (Distelfeld et al. 2007). A recent investigation of $\mathrm{Zn}$ translocation in wheat seeds structures proved the high levels of mobilizations of $\mathrm{Zn}$ into seed rachis and crease at late seed developmental stage (Stomph et al. 2011), which might be associated with the $\mathrm{N}$ remobilization into seeds at same developmental stage. Ultimately, nested-ANOVA shows that though haplotype at the GPC locus has significant effects on several seed components, it still explains a minor source of variation with respect to the genotype, suggesting other genes are also involved in the accumulations of $\mathrm{Sta}, \mathrm{TN}$ and Fe within this barley population.

In a word, we presented a comprehensive profile of barley seed components from 4 environments, with a remarkable high GEI in Phy, Phe, Fla and $\mathrm{P}_{\mathrm{i}}$ but relatively low GEI in $\mathrm{Zn}$ and $\mathrm{Fe}$. The segregations of GPC locus within the population and its strong effect on Fe suggested its significant influences on micro-elements. The dissections on $\mathrm{C}-\mathrm{N}$ balance highlighted the CNR2 as a key parameter for the interactions between macro- and macro-nutrients in barley seeds.

\section{Acknowledgements}

This work was supported by the China-Israel cooperation program grants from the Ministry of Science and Technology in China (No. 2013DFA32200), and the Department of Science and Technology in Guizhou Province [No. Qian Ke He Wai G Zi (2012)7011].

\section{References}

Ainsworth, E.A., Gillespie, K.M. 2007. Estimation of total phenolic content and other oxidation substrates in plant tissues using Folin-Ciocalteu reagent. Nature Protocols 2:875-877.

Bao, J., Kong, X., Xie, J., Xu, L. 2004. Analysis of genotypic and environmental effects on rice starch. 1. Apparent amylose content, pasting viscosity, and gel texture. J. of Agric. and Food Chem. 52:6010-6016.

Blanco, A., Mangini, G., Giancaspro, A., Givo, S., Colasuonno, P., Simeone, P., Signorile, A., De Vita, P., Mastrangelo, A.M., Cattivelli, L., Gadaleta, A. 2012. Relationships between grain protein content and grain yield components through quantitative trait locus analyses in a recombinant inbred line population derived from two elite durum wheat cultivars. Mol. Breeding 30:79-92.

Brankovic, G., Dragičević, V., Dodig, D., Zoric, M., Knežević, D., Žilić, S., Denčić, S., Šurlan, G. 2015. Genotype $\times$ environment interaction for antioxidants and phytic acid contents in bread and durum wheat as influenced by climate. Chilean J. of Agric. Res. 75:139-146. 
Caldwell, C.R., Britz, S.J., Mirecki, R.M. 2005. Effect of temperature, elevated carbon dioxide, and drought during seed development on the isoflavone content of dwarf soybean [Glycine max (L.) Merrill] grown in controlled environments. J. of Agric. and Food Chem. 53:1125-1129.

Distelfeld. A., Cakmak, I., Peleg, Z., Ozturk, L., Yazici, A.M., Budak, H., Saranga, Y., Fahima, T. 2007. Multiple QTL-effects of wheat $G p c-B 1$ locus on grain protein and micronutrient concentrations. Physiologia Plantarum 129:635-643.

Distelfeld, A., Korol, A., Dubcovsky, J., Uauy, C., Blake, T., Fahima, T. 2008. Colinearity between the barley grain protein content (GPC) QTL on chromosome arm $6 \mathrm{HS}$ and the wheat $G p c-B 1$ region. Mol. Breeding 22:25-38.

Ficco, D.B.M., Riefolo, C., Nicastro, G., De Simone, V., Di Gesù, A.M., Beleggia, R., Platani, C., Cattivelli, L., De Vita, P. 2009. Phytate and mineral elements concentration in a collection of Italian durum wheat cultivars. Field Crops Res. 111:235-242.

Gomez-Becerra, H.F., Erdem, H., Yazici, A., Tutus, Y., Torun, B., Ozturk, L., Cakmak, I. 2010. Grain concentrations of protein and mineral nutrients in a large collection of spelt wheat grown under different environments. J. Cereal Sci. 52:342-349.

He, J.S., Flynn, D.F.B., Wolfe-Bellin, K., Fang, J., Bazzaz, F.A. 2005. $\mathrm{CO}_{2}$ and nitrogen, but not population density, alter the size and $\mathrm{C} / \mathrm{N}$ ratio of Phytolacca americana seeds. Functional Ecol. 19:437-444.

Hell, R., Stephan, U.W. 2003. Iron uptake, trafficking and homeostasis in plants. Planta 216:541-551.

Holopainen, U.R.M., Rajala, A., Jauhiainen, L., Wilhelmson, A., Home, S., Kauppila, R., Peltonen-Sainio, P. 2015. Influence of sulphur application on hordein composition and malting quality of barley (Hordeum vulgare L.) in northern European growing conditions. J. Cereal Sci. 62:151-158.

Hristov, N., Mladenov, N., Djuric, V., Kondic-Spika, A., Marjanovic-Jeromela, A., Simic, D. 2010. Genotype by environment interactions in wheat quality breeding programs in southeast Europe. Euphytica 174:315324.

Jeuffroy, M.H., Casadebaig, P., Debaeke, P., Loyce, C., Meynard, J.M. 2014. Agronomic model uses to predict cultivar performance in various environments and cropping systems. A review. Agronomy for Sustainable Development 34:121-137.

Jia, Z., Tang, M., Wu, J. 1999. The determination of flavonoid contents in mulberry and their scavenging effects on superoxide radicals. Food Chem. 64:555-559.

Joshi, A.K., Crossa, J., Arun, B., Chand, R., Trethowan, R., Vargas, M., Ortiz-Monasterio, I. 2010. Genotype $\times$ environment interaction for zinc and iron concentration of wheat grain in eastern Gangetic plains of India. Field Crops Res. 116:268-277.

Latta, M., Eskin, M. 1980. A simple and rapid colorimetric method for phytate determination. J. of Agric. and Food Chem. 28:1313-1315.

Liu, K.S., Peterson, K.L., Raboy, V. 2007. Comparison of the phosphorus and mineral concentrations in bran and abraded kernel fractions of a normal barley (Hordeum vulgare) cultivar versus four low phytic acid isolines. J. of Agric. and Food Chem. 55:4453-4460.

Liu, Z., Cheng, F., Zhang, G. 2005. Grain phytic acid content in japonica rice as affected by cultivar and environment and its relation to protein content. Food Chem. 89:49-52

Mamo, B.E., Barber, B.L., Steffenson, B.J. 2014. Genome-wide association mapping of zinc and iron concentration in barley landraces from Ethiopia and Eritrea. J. Cereal Sci. 60:497-506.

Marwede, V., Schierholt, A., Möllers, C., Becker, H.C. 2004. Genotype $\times$ environment interactions and heritability of tocopherol contents in canola. Crop Sci. 44:728-731

Ozturk, L., Eker, S., Torun, B., Cakmak, I. 2005. Variation in phosphorus efficiency among 73 bread and durum wheat genotypes grown in a phosphorus-deficient calcareous soil. Plant Soil 269:69-80.

Pandian, S.S., Robin, S., Vinod, K.K., Rajeswari, S., Manonmani, S., Subramanian, K.S., Saraswathi, R., Kirubhakaran, A.P.M. 2011. Influence of intrinsic soil factors on genotype-by-environment interactions governing micronutrient content of milled rice grains. Aust. J. of Crop Sci. 5:1737-1744.

Parrott, D.L., Downs, E.P., Fischer, A.M. 2011. Control of barley (Hordeum vulgare L.) development and senescence by the interaction between a chromosome six grain protein content locus, day length, and vernalization. J. Exp. Bot. 63:1329-1339. 
Pearce, S., Tabbita, F., Cantu, D., Buffalo, V., Avni, R., Vazquez-Gross, H., Zhao, R., Conley, C.J., Distelfeld, A., Dubcovksy, J. 2014. Regulation of Zn and Fe transporters by the GPC1 gene during early wheat monocarpic senescence. BMC Plant Biol. 14:368.

Routaboul, J.M., Kerhoas, L., Debeaujon, I., Pourcel, L., Caboche, M., Einhorn, J., Lepiniec, L. 2006. Flavonoid diversity and biosynthesis in seed of Arabidopsis thaliana. Planta 224:96-107.

Scheible, W.R., Morcuende, R., Czechowski, T., Fritz, C., Osuna, D., Palacios-Rojas, N., Schindelasch, D., Thimm, O., Udvardi, M.K., Stitt, M. 2004. Genome-wide reprogramming of primary and secondary metabolism, protein synthesis, cellular growth processes, and the regulatory infrastructure of arabidopsis in response to nitrogen. Plant Physiol. 136:2483-2499.

Souza, E.J., Martin, J.M., Guttieri, M.J., O’Brien, K.M., Habernicht, D.K., Lanning, S.P., McLean, R., Carlson, G.R., Talbert, L.E. 2004. Influence of genotype, environment, and nitrogen management on spring wheat quality. Crop Sci. 44:425-432.

Stomph, T.J., Choi, E.Y., Stangoulis, J.C.R. 2011. Temporal dynamics in wheat grain zinc distribution: is sink limitation the key? Ann. Bot. 107:927-937.

Takahashi, M., Nozoye, T., Kitajima, N., Fukuda, N., Hokura, A., Terada, Y., Nakai, I., Ishimaru, Y., Kobayashi, T., Nakanishi, H., Nishizawa, N.K. 2009. In vivo analysis of metal distribution and expression of metal transporters in rice seed during germination process by microarray and X-ray Fluorescence Imaging of Fe, $\mathrm{Zn}, \mathrm{Mn}$, and $\mathrm{Cu}$. Plant Soil 325:39-51.

Triboi, E., Triboi-Blondel, A.M. 2002. Productivity and grain or seed composition: a new approach to an old problem - invited paper. Eur. J. Agron. 16:163-186.

Uauy, C., Distelfeld, A., Fahima, T., Blechl, A., Dubcovsky, J. 2006. A NAC gene regulating senescence improves grain protein, zinc, and iron content in wheat. Science 314:1298-1301.

White, P., Veneklaas, E. 2012. Nature and nurture: the importance of seed phosphorus content. Plant Soil 357:1-8.

Zhang, G., Chen, J., Wang, J., Ding, S. 2001. Cultivar and environmental effects on $(1 \rightarrow 3,1 \rightarrow 4)-\beta$-D-glucan and protein content in malting barley. J. Cereal Sci. 34:295-301.

\section{Electronic Supplementary Material (ESM)}

Electronic Supplementary Material (ESM) associated with this article can be found at the website of CRC at http://www.akademiai.com/content/120427/

Electronic Supplementary Table S1. Average temperature, $\mathrm{pH}$, organic matter content and element concentrations in the soil of three field locations in China

Electronic Supplementary Table S2. Two-way ANOVA of seed components from 4 environments

Electronic Supplementary Table S3. Nested ANOVA of seed components from 4 environments, genotype nested within haplotype $\mathrm{Hvm} 74$

Electronic Supplementary Figure S1. Comparative average of barley seed components, carbon/nitrogen ratio, HKW and SKW in 4 environments 